\title{
ABDOMINAL PREGNANCY - A RARE AND CHALLENGING DIAGNOSIS
}

\author{
Pawel Sadlecki ${ }^{1}$, Marek Grabiec ${ }^{1}$, and Malgorzata Walentowicz-Sadlecka ${ }^{1}$ \\ ${ }^{1}$ Nicolaus Copernicus University
}

January 11, 2021

\begin{abstract}
Abdominal pregnancy is a very rare, life-threatening form of ectopic pregnancy, in which implantation occurs within the peritoneal cavity. The advantages of a laparoscopic approach over a laparotomy in this setting include a reduced estimated blood loss, a shorter operating time, reduced analgesic requirements, shorter hospital stay and convalescence.
\end{abstract}

\section{Hosted file}

Abdominal_pregnancy.pdf available at https://authorea.com/users/388717/articles/503486abdominal-pregnancy-a-rare-and-challenging-diagnosis 